\title{
Protein Complex Subunit
}

National Cancer Institute

\section{Source}

National Cancer Institute. Protein Complex Subunit. NCI Thesaurus. Code C20184.

Used for classifying a protein or peptide that does not have a perceptible function before it is assembled into a functional complex. 